\title{
Way-finding On-Board Training for Maritime Vessels
}

\author{
S. Tvedt ${ }^{1}$, H. Oltedal ${ }^{1}$, B.M. Batalden ${ }^{2}$, M. Oliveira ${ }^{3}$ \\ ${ }^{1}$ Haugesand University College, Norway \\ ${ }^{2} \mathrm{UiT}$ - The Artic University of Norway, Norway \\ ${ }^{3}$ Sintef, Norway
}

\begin{abstract}
In the maritime industry, it is of vital importance that personnel onboard ships are familiarized with the ship's layout, along with safety equipment and processes for safeguarding of the individual seafarer and the ship's crew. In fact, international maritime regulations require that all personnel employed or engaged on a seagoing ship receive proper familiarization training. However, several studies have identified lack of familiarization as a contributing factor to maritime incidents. There are several challenges associated with the current familiarization practices, namely cost, difficulty in optimizing planning, variation in practices in familiarization and the experience of the facilitator of familiarization process. This paper presents a study consisted of 58 students comparing traditional and virtual familiarization. The study found that there were no significant differences between real and virtual familiarization, and some support for differences between the familiarization conditions for single waypoints. Individual differences are clearly more important than the mode of familiarization.
\end{abstract}

\section{Introduction}

In the maritime industry, namely regarding logistics and transport, seafarers are exposed to a high diversity of safety and security risks as potential occupational accidents, disasters and piracy (Oldenburgh, et al., 2010). In many of these incidents, the response time often plays a critical role in making the optimal decision, with limited information and short timeliness, towards achieving a successful outcome. A key factor to the decision making process is adequate familiarization of the vessel's design, equipment and outfitting. In fact, international maritime regulations require that all personnel employed or engaged on a seagoing ship receive proper familiarization training (IMO, 2011, IMO, 2014). However, there is a lack of standardization of vessel design, which leads to significant amount of diversity in layouts and structure, making familiarization a tailored process applied to each vessel. It is also important to denote that on certain types of vessels, such as offshore support vessels, a great number of people may not be part of the ordinary marine crew. However, this does not exempt them from receiving basic familiarization training. The importance of familiarization cannot be overemphasized as demonstrated through the additional statutory requirements for familiarization through industry standards such as the Common Marine Inspection Document (CMID) and Offshore Vessel Inspection Database (OVID) (IMCA 2013, OCIMF 2010, OCIMF 2011).

When analyzing existing familiarization practices amongst different shipping companies, one can distil a common approach which is based on the provision of a guided tour throughout key points within the vessel. This tour corresponds to relevant safety locations and routes through the vessel between locations. The familiarization practices also include the demonstration of particular safety equipment. Atypically, the familiarization tour is conducted by a qualified person such as the safety officer of the vessel. 
The analysis of current familiarization practices as performed today (Tvedt and Oltedal, 2013; Vaagland, 2014) have identified common challenges that compromise the effectiveness of the training. These challenges can be distilled into:

- Cost. The familiarization is a simple enough task, but it still requires a significant amount of time to be adequately carried out, which disrupts other tasks and operations, meaning that work by the security officer is not carried out;

- Scale. As a result of the vessels' indoor environment, it is necessary to conduct the tours with relatively small number of seafarers. This implies considerable inefficiency, in particular when considering that personnel often arrive at different times, which invalidate any attempt to optimize the tours;

- Practice. The personal ability of the safety officer in conveying the necessary relevant information in an effective and engaging manner so all individuals within the group have equal potential of acquiring the imparted knowledge.

- Context. The positioning of the individuals within the group and their distance from the officer delivering the familiarization of the vessel

So even though the statutory requirements and procedures for ship familiarization are met, recent research indicates that defective familiarization is an explanatory factor in many accidents (Batalden et.al, 2014; Kum et al, 2015).

In the attempt of addressing these challenges, the Norwegian shipping company Østensjø ASA engaged in a research project to study the impact of gaming technologies, namely the use of Virtual Reality (VR) in familiarization. As such, a HSE familiarization simulator was developed based on a real inspection, maintenance and repair (IMR) vessel currently involved with petroleum-related deep sea operations in the North Sea - the Edda Fauna vessel. This paper reports on the exploratory research in the use of serious games as a potential viable alternative, involving a total of 58 participants. The main aim of the study was to compare the effectiveness of serious games compared to real-world familiarization. Consequently, an experimental design involving two groups was used, with half of the participants being exposed to the current familiarization practice, whilst the remainder half being exposed to the virtual familiarization facilitated by a serious game modelled on the same vessel as reality. As part of characterizing the participants, a set of four distinct pre-tests were carried out: spatial manipulation, spatial orientation, visual memory and the use of Call for of Duty 4. After the initial exposure, all participants were tested in their knowledge of the vessel by recognizing particular waypoints like the "Fire Station" and exits to the "Muster Station".

The paper is structured into a further 5 sections, starting with an overview of the relevant principles in cognitive psychology and virtual reality underpinning the study on way finding training using a serious game. Section 3 describes the simulator environment of the serious game and the study methodology, along with the hypothesis, is covered in section 4 . The key results are presented in section 5, with an in-depth analysis, discussion and conclusion in the final section 6 .

\section{Background}

The essence of the process of familiarization of a maritime vessel is to facilitate seafarers in their understanding of the vessel's layout, thus enabling them to identify key waypoints and learn appropriate routes between the most critical waypoints. The main aim for familiarization is to ensure personal safety and safe operation of the ship. 
There are two fields of study relevant for understanding the individual's familiarization process of their surrounding spatial environment:

- Cognitive Psychology with regards to how individuals process their surroundings from a cognitive perspective;

- Virtual Reality with regards to how individuals navigate within virtual environments.

\subsection{Cognitive Psychology}

The individual's processing of their surrounding environment relies on the use of spatial memory (Curiel \& Radvansky, 1998), which consists of a cognitive process where individuals build and update their mental representation of space otherwise designated as cognitive maps (Howard and Kerst, 1981) based on their own spatial position and orientation in relation to their environment and objects contained therein (see Hegarty, 2006, for review). However, according to (Tversky, 2005) it is more likely that people do not construct accurate structural representations of reality, but rather collation of spatial information in recognisable clumps, similar to cognitive collages.

Nevertheless, the three stage development of the cognitive representation of large-scale navigational space has a strong foothold in cognitive psychology (Siegel \& White, 1975): Initially, a person will focus on important locations in the environment. The knowledge at this stage consists of sets of disconnected landmarks. More exposure to the environment will enable a person to link the landmarks together into routes. This knowledge is termed route representation. With additional exposure, some people develop a map-like representation of the environment that is flexible and allows people to infer new routes and short cuts. This knowledge is called survey representation. Chrastil and Warren (2015) also introduces a mediating level called "graph knowledge" between route and survey knowledge. This graph knowledge contains the topological information and the connectivity of the environment, but not the metric information about distances contained in survey knowledge.

\subsection{Active and passive contributions to spatial learning}

In their review of research on active and passive learning, Chrastil and Warren (2012) point out that despite the intuitiveness and anecdotal evidence of the value of active spatial learning, the research literature has yielded mixed results. They go on to argue that this has to do with confounding different aspects of activeness, which warrants a more sophisticated treatment of activeness. They then go on to distinguish five components of active learning associated with differing results:

1. idiothetic information, acquired by physical movement in space;

2. decision making about turns during exploration;

3. attention to place-actions and relevant spatial relations;

4. the different encoding subunits of working memory involved in encoding of route- and survey information;

5. the facilitation of mental manipulation for spatial learning.

Idiothetic information have been shown to contribute to metric survey knowledge - that is awareness of distances in a landscape (Chrastil \& Warren, 2012). Decision making has generally not been shown to matter - passive explorers that tag along learn just as much. This might be explained by demand characteristics in the experiment prompting passive explorers to also pay attention. However, new insights also points to benefits of decision making for graph knowledge (Chrastil \& Warren, 2015). Attention to place-actions and spatial relations have been shown to help route and survey information, although landmarks and spatial boundaries are learned without special attention (at least in experiments) (Chrastil \& Warren, 2015). There's also increasing evidence that route- and survey learning are more dependent on 
the working memory, and interference studies show that verbal- and executive memory plays a role in encoding, but that visuo-spatial working memory is crucial for both encoding and retrieving spatial memory (Chrastil \& Warren, 2015). For wayfinding this means that verbal, executive, and visuo-spatial distractors during encoding will be detrimental in acquiring routeand survey knowledge. Although more research is needed, it has been shown that explorers actively using a map to find a route performed better than explorers given the same map with auditory instructions about which way to turn (Münzer, Zimmer, Schwalm, Baus, \& Aslan, 2006).

\subsubsection{Multi-level Physical Structures}

Wayfinding research represents an extensive body of research relevant to the purpose of the present study, although the field has paid little attention to wayfinding onboard ships. Hölscher, Meilinger, Crachliotis, Brösamle, and Knauff (2006) focus on a point of direct interest for any familiarization training onboard ships - that of the special case of multilevel buildings. The rapid direction changes involved in climbing stairs are thought to be a central problem here. Also, Soeda, Kushiyama, and Ohno (1997) identify a common error with wayfinders in assuming that the topology of the floor plans of different levels are identical.

\subsubsection{Additional problematic features}

Other problematic features with the layout of modern offshore vessels have long been classical focal points for the field. Weisman (1981) presents a typology of four classes of environmental variables that shape wayfinding situations:

i) visual access;

ii) degree of architectural differentiation;

iii) use of signs and room numbers;

iv) floor plan configuration.

\subsection{Navigation in Virtual Environments}

Navigation (Bowman, et al., 2004) is most likely the most basic interaction activity undertaken by users within a virtual environment since it is necessary to navigate to a place before performing any action. There is a rich variety of ways in which navigation can be carried out, depending on how orientation is established and the speed at which travel is undertaken. An overview of possible techniques is given in (Mine, 1995). Some of the navigation techniques require a selection operation of the target destination and combine them with a particular means of locomotion. As a person navigates through their environment, multiple sensorial cues contribute to the cognitive updating process, and as demonstrated in (Klatzky, 1998), the lack proprioceptive cues can lead to incoherency of the cognitive maps, in particular with regards to overturning. This is an atypical challenge associated to instantaneous travel mechanisms where a person may teleport themselves from one point to another, which studies such as (Bowman et al 1997) have demonstrated that people may feel disoriented when deprived of spatial awareness during the trajectory of travel as a result of jumping immediately to their destination. So although teleporting would provide the shortest means of travelling, it is the least sympathetic to the users, possibly due to the lack of a counterpart in the real world.

The research on way-finding and navigation has been an active line of research in virtual reality since the inception of the field, with studies measuring the learning effect of virtual versus real world training. It is hard to assess the most effective navigation technique for a virtual environment and how it fits into the user's cognitive collage (Fairchild, et al 1993). To distinguish between the usability of each technique, (Bowman, et al., 1997) proposes a taxonomy of virtual travel techniques, along with quality measures to assess their usability. A testbed evaluation study of basic interaction techniques (Bowman, et al., 2001) yields the following useful recommendations for navigation design in virtual environments: 
- Navigation involving the user in steering the movement produces the most intuitive interface and can be mapped onto the user in one of three ways, direction of the head, direction of the body, or hand gesture. These techniques demonstrate a higher level of precision and control of movement;

- Navigation based on target selection, such as ray-casting, may have an impact on the design of the virtual environments to compensate for the inaccuracy of the technique;

- Navigation based on manipulation techniques, such as Hand-centred Object Manipulation Extending Ray-casting (HOMER) (Bowman \& Hodges, 1997) and Go-Go Interaction (Poupyrey, et al., 1996), should not be used in virtual environments where travel is frequent and usability times are high, due to the resulting discomfort;

- Any navigation technique that does not have cognitive mapping to physical travelling may perform worse than the more natural techniques. This property is not exclusive to threedimensional VEs, as users within text-based Multi-User Dungeons also experience disorientation whenever confronted with non-Euclidian spaces.

Although there are three dimensions to a virtual environment, most of the navigation is done in two dimensions, so one may wonder about the effectiveness of any method based on maps when considering navigation in all three dimensions since the user experiences greater difficulty in gathering and assessing spatial information (Bowman et al 1999). Consequently, there are many forms of travel, which presents an interesting challenge to achieve a unifying framework that encompasses all possible scenarios. Classic examples are:

- The use of World In Miniature (WIM) interface (Pausch, et al., 1995). The concept consists of the user having a smaller 3D miniature of the environment that allows them to see and select their destination without suffering from any occlusions to their line of sight derived from the structure of the model. This mechanism is generalised in (Viega, 1996), which presents the concept of using a lens frustum with specific viewing properties, such as transparency or volume reduction.

- Another navigational aid is the possibility of empowering the user with the ability to see through obstacles (e.g.: walls). The effectiveness of using transparency as a navigational aid was studied in (Chittaro \& Scagnetto, 2001), which demonstrated that the method did improve users' navigation. The same study also validated that providing the user with the capability of having a bird's-eye-view yielded even better results than using the transparency mechanism.

\subsection{Limitations concerning input quality in virtual reality}

Studies have demonstrated that the use of games lead to an improvement of cognitive skills, as evidenced in (Bavelier and Green 2016). In particular, some studies reflect improvement of spatial skills towards better spatial memory, as in the case of (Sanchez, 2012, Cherney, 2008, Feng, et al., 2007, Terlecki, 2008).

However, quality of input devices plays a crucial role in the user's performance in selecting objects within the virtual environment. This is evidenced in a study (Richard 1996), where the subjects who had haptic feedback and a stereoscopic visual display with high refresh rate performed a task much better than those subjects who had a desktop display without the lower fidelity devices. In similar fashion, anything detrimental to the quality of the devices, such as latency (Ware 1994), has a negative impact on the user performance in object interaction. Another detrimental factor in the performance of individuals whilst navigating a virtual environment is the cognitive dissonance resulting from the limitations imposed by the use of input devices such as the keyboard and mouse (Jadhav \& Kanse, 2015). 


\section{Simulator Environment}

In the pursuit of addressing the challenges with regards to familiarization, the Norwegian shipping company Østensjø AS developed a Health and Safety Environment (HSE) simulator modelled on the Edda Fauna maritime vessel. With regards to the modelling of the environment, some simplifications were made as evidenced in the comparative snapshots of the same view point from the simulator and reality captured in Figure 1. In addition to simplifications, the doors of passageways were always modelled open in the virtual familiarization whilst in reality, those same doors were always closed. However doors not intended as part of the familiarization were typically modelled as always closed, whereas in real life these were often open - such as the door to a client office, to the left in the picture.
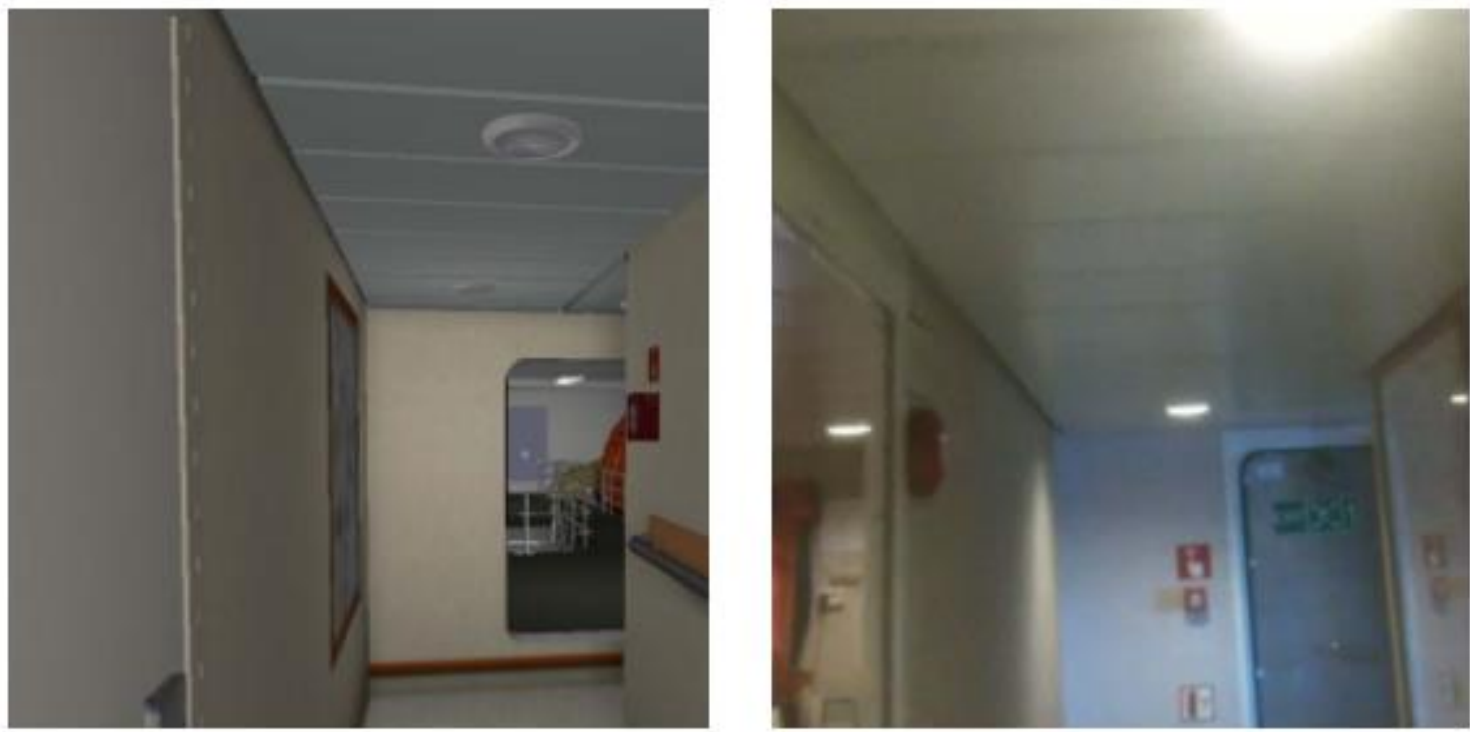

Figure 1 - Snapshots for the same view point in Edda Fauna in the simulator (left image) and in reality (right image)

A wayfinding route was developed comprising of six posts. This was based on the HSE simulator, official familiarization procedures on the vessel, and official "Safety plans". These six posts were taken from the ten posts given in the HSE simulator and are all presented at traditional familiarizations, as declared by official procedures and confirmed by the pilot participants. The posts and their sequence have been tested in earlier pilot studies (Tvedt \& Oltedal, 2013). The time taken to find each of the six posts (Table 1) were recorded with a stop watch by the instructing researcher not counting time spent on instruction.

Table 1 - Wayfinding route with waypoints

\begin{tabular}{lllll}
\hline Waypoint & Label & Situation & Description & Shortest route of access \\
\hline WP0 & Reception & $\begin{array}{l}\text { A deck, aft } \\
\text { in the } \\
\text { interior on } \\
\text { Starboard } \\
\text { side } \\
\text { D deck, aft } \\
\text { in the } \\
\text { interior on } \\
\text { Port side }\end{array}$ & $\begin{array}{l}\text { Point of } \\
\text { entering the } \\
\text { ship }\end{array}$ & $\begin{array}{l}\text { Main exit to } \\
\text { muster station }\end{array}$ \\
WP1 & Exit 1 & $\begin{array}{l}\text { Follow the hall to staircase, } \\
\text { climb 3 levels, exit staircase to } \\
\text { the right and move down the } \\
\text { hall through the fire door }\end{array}$ \\
\hline
\end{tabular}




\begin{tabular}{|c|c|c|c|c|}
\hline Waypoint & Label & Situation & Description & Shortest route of access \\
\hline WP2 & Exit 2 & $\begin{array}{l}\text { D deck, aft } \\
\text { in the } \\
\text { interior on } \\
\text { Port side }\end{array}$ & $\begin{array}{l}\text { Alternative exit } \\
\text { to muster } \\
\text { station }\end{array}$ & $\begin{array}{l}\text { Turn } 180^{\circ} \text {, down stairs } 1 \text { level } \\
\text { through door, follow hall right } \\
\text { then left, turn right when } \\
\text { hallroom opens up, then right } \\
\text { again into hall, than past door to } \\
\text { down staircase and up next } \\
\text { staircase } 1 \text { level and then } \\
\text { straight ahead. }\end{array}$ \\
\hline WP3 & Hospital & $\begin{array}{l}\text { B deck, fore } \\
\text { in the } \\
\text { interior on } \\
\text { Starboard } \\
\text { side }\end{array}$ & $\begin{array}{l}\text { Simple } \\
\text { operation room } \\
\text { with medical } \\
\text { equipment and } \\
\text { drugs }\end{array}$ & $\begin{array}{l}\text { Turn } 180^{\circ} \text {, down stairs } 1 \text { level, } \\
\text { then follow hall and turn left } \\
\text { into hall-room and exit hall- } \\
\text { room on the first door to the } \\
\text { right. }\end{array}$ \\
\hline WP4 & $\begin{array}{l}\text { Fire } \\
\text { station } 1\end{array}$ & $\begin{array}{l}\text { Main deck, } \\
\text { slightly aft in } \\
\text { the interior } \\
\text { on Port side }\end{array}$ & $\begin{array}{l}\text { Room with } \\
\text { firefighter } \\
\text { equipment } \\
\text { including } \\
\text { smoke diving } \\
\text { kits }\end{array}$ & $\begin{array}{l}\text { Enter staircase, down stairs } 3 \\
\text { levels, exit staircase to the left } \\
\text { and turn left, than immediately } \\
\text { right and straight down the } \\
\text { aisle, door to the right. }\end{array}$ \\
\hline WP5 & $\begin{array}{l}\text { Fire } \\
\text { station } 2\end{array}$ & $\begin{array}{l}\text { B deck, fore } \\
\text { in the } \\
\text { interior on } \\
\text { Starboard } \\
\text { side }\end{array}$ & $\begin{array}{l}\text { Room with } \\
\text { firefighter } \\
\text { equipment } \\
\text { including } \\
\text { smoke diving } \\
\text { kits }\end{array}$ & $\begin{array}{l}\text { Turn right, then left and enter } \\
\text { staircase to the right. Up } 3 \\
\text { levels, exit staircase to the right, } \\
\text { then turn immediately left, door } \\
\text { to the left. }\end{array}$ \\
\hline WP6 & Reception & $\begin{array}{l}\text { A deck, aft } \\
\text { in the } \\
\text { interior on } \\
\text { Starboard } \\
\text { side }\end{array}$ & $\begin{array}{l}\text { Point of } \\
\text { entering the } \\
\text { ship }\end{array}$ & $\begin{array}{l}\text { Turn left, and enter staircase on } \\
\text { the right, down two levels and } \\
\text { exit staircase to the right, then } \\
\text { turn right and follow hallway }\end{array}$ \\
\hline
\end{tabular}

\section{Study Methodology}

A relevant study of the impact of familiarization within a maritime vessel is found in a feasibility study on the use of virtual environments in the training of fire-fighting (Williams, et al., 1997) where there were two phases to the study. The first phase, and most relevant to this paper, consisted on the research of the use of the virtual environment in reducing both the time in navigating a fictitious vessel and the number of errors along a single path. The study focused on the comparative analysis of the two chosen performance indicators, without assessing the impact of the individual waypoints along the route. Additionally the study did not research the impact of prior gaming experience on the spatial memory of the study participants and the subsequent impact on their performance.

\subsection{Hypothesis}

Relevant dimensions of spatial memory for the present study and how they relate to the traditional and virtual familiarization are summed up in Table 2. With regards to the familiarization conditions, the different strengths and weaknesses should cancel each other out 
in overall measure. However, different single waypoints might differentially influenced by the same strengths and weaknesses, thus some waypoints favouring traditional- and some favouring virtual familiarization.

Table 2 - Summary of Spatial Dimensions in Relation to Traditional and Virtual Familiarization

\begin{tabular}{|c|c|c|c|c|}
\hline \multirow{3}{*}{\multicolumn{2}{|c|}{$\begin{array}{l}\text { Spatial Memory } \\
\text { Dimension }\end{array}$}} & \multicolumn{3}{|l|}{ Familiarization } \\
\hline & & \multirow[b]{2}{*}{ Traditional } & \multirow[b]{2}{*}{ Virtual } & \multirow[t]{2}{*}{ Observations } \\
\hline & & & & \\
\hline \multicolumn{2}{|c|}{$\begin{array}{l}\text { Active } \\
\text { manipulation vs } \\
\text { Passive Learning }\end{array}$} & Passive learning & Active learning & $\begin{array}{l}\text { Traditional familiarization entails passively } \\
\text { being guided, whereas the HSE simulator } \\
\text { involves post finding. }\end{array}$ \\
\hline \multirow{3}{*}{$\begin{array}{l}\text { Multi- } \\
\text { level }\end{array}$} & $\begin{array}{l}\text { Stair } \\
\text { cases }\end{array}$ & $\begin{array}{l}\text { Seafarers } \\
\text { physically move } \\
\text { between levels, } \\
\text { but passively }\end{array}$ & $\begin{array}{l}\text { Seafarers use } \\
\text { keyboard/mouse } \\
\text { for navigation }\end{array}$ & $\begin{array}{l}\text { The Edda Fauna has } 5 \text { distinct decks (open } \\
\text { to visitors) and each segment of the route } \\
\text { entails level transition }\end{array}$ \\
\hline & $\begin{array}{l}\text { Lacking } \\
\text { intercon- } \\
\text { nections }\end{array}$ & $\begin{array}{l}\text { The conservation } \\
\text { of energy } \\
\text { suggests that the } \\
\text { guided tour } \\
\text { moves } \\
\text { systematically } \\
\text { along the central } \\
\text { staircase }\end{array}$ & $\begin{array}{l}\text { Seafarers can } \\
\text { employ the stair } \\
\text { strategy, but are } \\
\text { not prompted to }\end{array}$ & $\begin{array}{l}\text { Traditional familiarization tends to move } \\
\text { the group up and down the central staircase } \\
\text { without necessarily pointing out the strategy } \\
\text { Seafarers showed very different preference } \\
\text { for wayfinding strategies }\end{array}$ \\
\hline & $\begin{array}{l}\text { Dissimi- } \\
\text { lar floor } \\
\text { layouts }\end{array}$ & Not a theme & $\begin{array}{l}\text { Not a theme, but } \\
\text { learner paced } \\
\text { learning could } \\
\text { make it easier to } \\
\text { notice }\end{array}$ & $\begin{array}{l}\text { It is not clear from the familiarization that } \\
\text { even the security officer are conscious of } \\
\text { the dissimilar floor layouts. Some seafarers } \\
\text { varied markedly in tendency to get lost } \\
\text { during the simulator tasks because of the } \\
\text { dissimilar floor design }\end{array}$ \\
\hline \multicolumn{2}{|c|}{$\begin{array}{l}\text { Problematic } \\
\text { features }\end{array}$} & $\begin{array}{l}\text { Occluded line of } \\
\text { sight and full- } \\
\text { fidelity of reality }\end{array}$ & $\begin{array}{l}\text { Full line of sight } \\
\text { along paths and } \\
\text { simplification of } \\
\text { environment }\end{array}$ & $\begin{array}{l}\text { The modelling of Edda Fauna is a } \\
\text { simplification of reality }\end{array}$ \\
\hline \multicolumn{2}{|c|}{$\begin{array}{l}\text { Attention and } \\
\text { distractors }\end{array}$} & $\begin{array}{l}\text { Learning in } \\
\text { groups, in a busy } \\
\text { ship at port, } \\
\text { whilst also } \\
\text { managing first } \\
\text { impressions. } \\
\text { Security officer } \\
\text { managing the } \\
\text { attention between } \\
\text { competing spatial } \\
\text { information }\end{array}$ & $\begin{array}{l}\text { one to one learner } \\
\text { - machine } \\
\text { interface, learner } \\
\text { paced. } \\
\text { Simulator does not } \\
\text { manage attention } \\
\text { between competing } \\
\text { spatial information } \\
\text { (such as waypoints } \\
\text { in close proximity) }\end{array}$ & $\begin{array}{l}\text { At harbor there was busy activity on board } \\
\text { the Edda Fauna with personnel preparing } \\
\text { for voyage and varying degrees of } \\
\text { disturbance from fellow participants. The } \\
\text { HSE Simulator was clinically void of } \\
\text { disturbances but did little in terms of } \\
\text { guiding the participants to sort the } \\
\text { information. E.g. waypoints could be } \\
\text { "ticked" without pausing to notice where or } \\
\text { what they were. }\end{array}$ \\
\hline
\end{tabular}

Hence, the experimental design of the design reported by this paper were shaped by the following two hypothesis:

- H1: There are no overall difference between the virtual and the traditional familiarization condition on way-finding time.

- H2: There will be differences between the familiarization conditions based for single waypoints. 
An experimental post-test equivalent control group design with two groups was used. The groups received either traditional or virtual familiarization on the ship Edda Fauna before performing one individual way-finding trial on-board the ship.

\subsection{Participants}

58 students were recruited from the local high school and the local University College, studying maritime subjects, either nautical subjects or maritime engineering. The sample was a homogenous group predominantly in their twenties, and mostly men (87,9\%). Although all participants had a certain familiarity with ships and the maritime sector in general, participants with familiarity to the Edda Fauna was excluded along with one participant who openly lost interest in the experiment.

\subsection{Procedures}

The experiment was run on three different days, one for the college students, one for the engineering high school students, and one for the nautical high school students. For each experiment day, all participants were randomly assigned to either traditional or virtual familiarization and were familiarized before the wayfinding started:

- The traditional familiarization was performed by the second mates on watch which is standard procedure. Virtual familiarization was arranged by the project leader in a seminar room onboard the ship, using the Edda Fauna HSE simulator. The project leader then arranged a random sequence of participants with random assignment of researchers so that researchers were blind to the treatment, and there were no differences between treatment groups in order or assignment to researcher.

Participants were instructed individually according to a written instruction form, with optional instructions to guide the completion of each post with the least possible instructor interference. The following is an illustrative excerpt from the procedures (translated from Norwegian).

Say: "The muster station is where one gathers for evacuation of the ship find the muster station"

[Start stopwatch.]

[Follow the participant without going in his/her way or guiding them in any particular direction. Focus on studying the participant discretely and openly without commenting or showing expectations or surprise connected to route choices. When the participant has marked the destination, stop the watch and say: "Thank you, this is the muster station".]

[If the participant does not mark the destination sufficiently, but appears to think so, say: "Remember to mark the destination by walking up to it and say 'here"'.]

[If the participant marks an incorrect destination, say: "No, this is not the muster station."]

Finally, visuospatial skills were measured prior to the visit on board the ship for the university college students, and after the wayfinding test for the two other student groups. Importantly, this difference in administration was assigned equally across all other conditions in that all variables were balanced for each experiment day. 


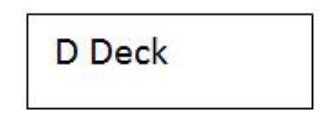

C Deck

\section{B Deck}

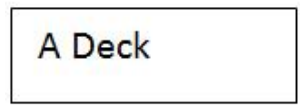

Main Deck
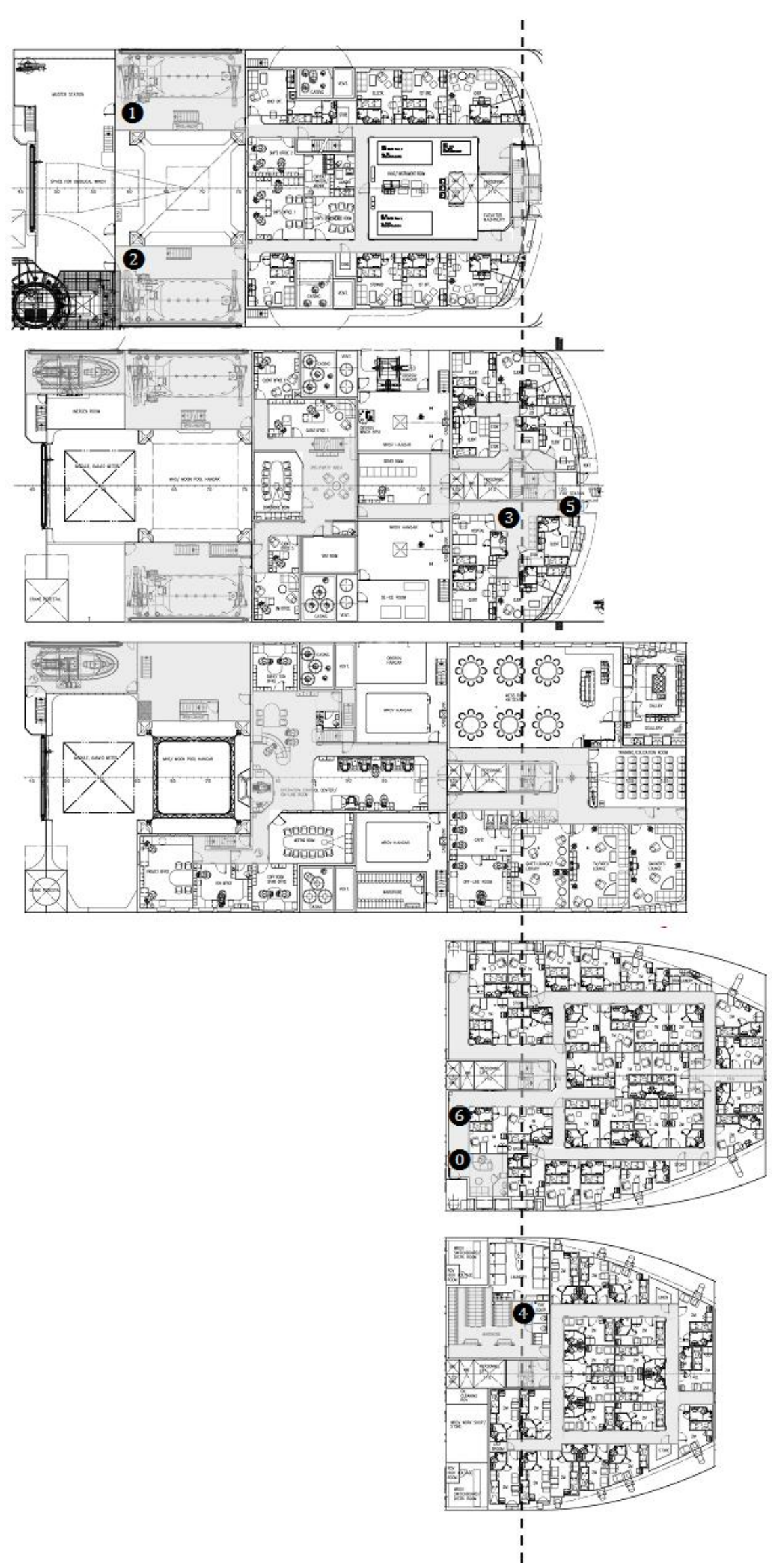

Figure 2 - Level plan with waypoints 
Figure 2 illustrates the different levels of the interior aboard Edda Fauna that was part of the experiment. The discontinuous line marks the point of alignment of the levels through the central staircase. Hallways, staircases and open hall areas relevant for the wayfinding is marked in grey. The waypoints are marked with numbered tags in the figure.

\subsection{Equipment and measurements}

The Edda Fauna HSE simulator is a PC-based desktop first person perspective (FPP) simulator, similar in control and experience to typical First Person Shooter (FPS) games for PC. The HSE simulator was installed on 6 identical 17" laptops typical for the consumer market which were equipped with external mouse.

The familiarization was performed according to the standard procedures and is a safety familiarization given to everyone staying on the ship outside of the crew running the ship. That is to say they are not familiarized in terms of running the ship or given special tasks in safety and evacuation plans, but are shown safety relevant cites and equipment. The familiarization was performed during three quarters of an hour with a maximum of 12 participants.

A wayfinding route was developed comprising of six posts (See Table 1 and Figure 2. This was based on the HSE simulator, official familiarization procedures on the vessel, and official "Safety plans". These six posts were taken from the ten posts given in the HSE simulator and are all presented at traditional familiarizations, as declared by official procedures and confirmed by the pilot participants. The posts and their sequence have been tested in earlier pilot studies, and were found to be sufficient and practically viable (Tvedt \& Oltedal, 2013). The time taken to find each of the six posts were recorded with a stop watch by the instructing researcher not counting time spent on instruction.

The participants were tested on visuospatial skills with the paper folding test (PF) and on FPS gaming skills by performing the introduction route on Call of Duty IV (COD) as indicated in Figure 3.

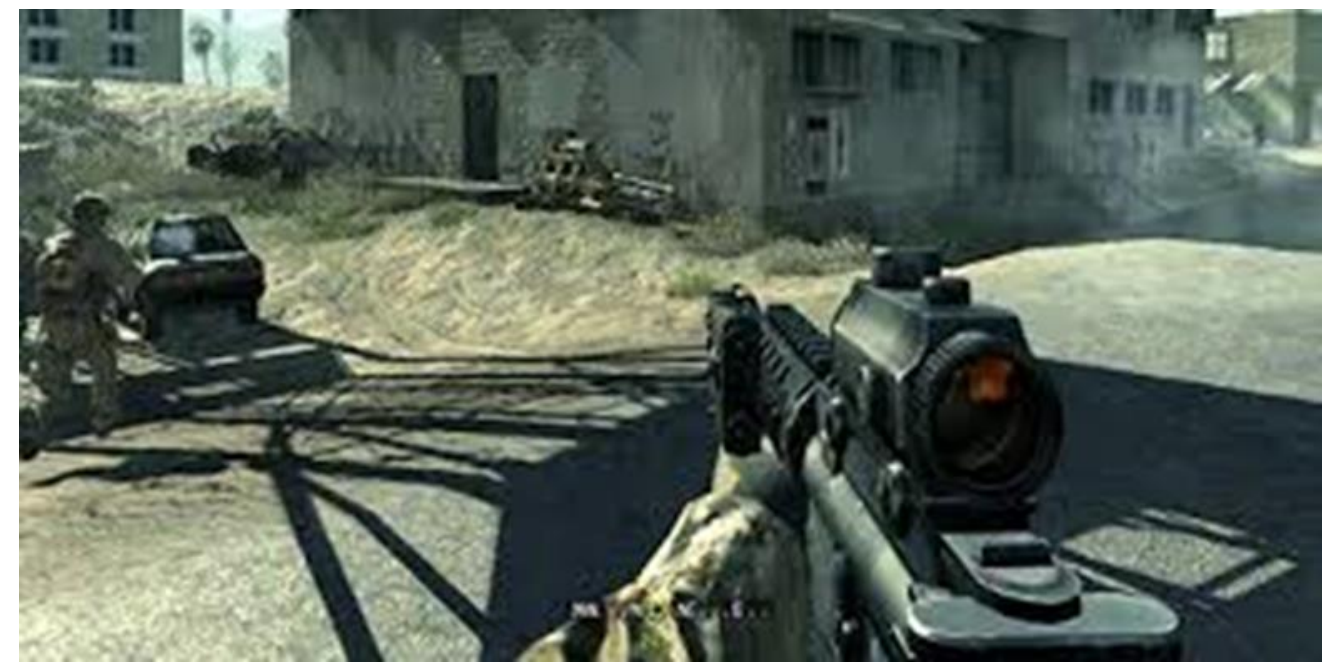

Figure 3 - snapshot of COD

The Paper Folding test involves showing participants a sequence of folds in a piece of paper, through which a set of holes is then punched. The participant is then presented with a set of unfolded papers with holes and must choose which one corresponds to the one they have just seen. To succeed, the participant must mentally rotate the paper. A sum score is then computed from the number of correct answers, which is the PF score. COD is a popular FPS game that has been well known among gamers. However, the particular instalment of the game was some years old at the time of the experiment, ensuring that none of the participants had recent 
experience with the particular instalment. The first instructional section of the game was employed, where the gamer is instructed on basic avatar movement and use of firearms, and timed through a route that requires the player to move avatar through virtual space and hit targets using a firearm. These tasks requires the participant to employ some basic virtual wayfinding and basic understanding of three dimensional virtual space involved in shooting, as well as basic avatar control with mouse- and keyboard. The time used to complete the route equals the COD score.

\subsection{Ethics}

Informed consent was given by all participants and necessary approval was gathered from the Norwegian Social Science Data Services (NSD).

\subsection{Analysis}

Pilot study power analyses revealed that treatment groups with $n>10$ would achieve effect sizes over Cohen's (1988) suggested default level of .80. Descriptive statistics and t-tests were performed with IBM SPSS Statistics 23. Hodges' g and Hodges g' confidence intervals were computed with $\mathrm{R}$ version 3.23 with compute.es package version $0.2-4$.

\section{Results}

Descriptive statistics of waypoint timings for the traditional and the virtual treatment conditions are given in Table 3.

Table 3 - M and SD of raw scores and Z scores for waypoint times and skills tests, as well as t-tests, Hodges' $\mathrm{g}$ and $95 \% \mathrm{Ci}$

\begin{tabular}{cccccccccc}
\hline \multirow{2}{*}{ Waypoint } & Treat & $\boldsymbol{n}$ & \multicolumn{1}{c}{$\boldsymbol{M}$} & \multicolumn{1}{c}{ SD } & \multicolumn{1}{c}{$\boldsymbol{M}$} & $\boldsymbol{S} \boldsymbol{D}$ & $\mathbf{t}$ & $\mathbf{d f}$ & $\mathbf{g}[\mathbf{9 5 \%}$ CI of g] \\
\hline MWP & Trad. & 28 & 95.77 & 39.88 & -0.06 & 0.50 & -.840 & 54.00 & $-0.22[-0.75,0.31]$ \\
& Virt. & 28 & 107.08 & 48.17 & 0.06 & 0.62 & & & \\
WP1 & Trad. & 28 & 175.04 & 113.55 & 0.22 & 1.06 & 1.696 & 52.01 & $0.45[-0.09,0.98]$ \\
& Virt. & 28 & 135.75 & 94.64 & -0.22 & 0.87 & & & \\
WP2 & Trad. & 28 & 79.54 & 60.55 & -0.07 & 0.93 & -.538 & 54.00 & $-0.14[-0.67,0.39]$ \\
& Virt. & 28 & 92.93 & 80.33 & 0.07 & 1.04 & & & \\
WP3 & Trad. & 28 & 70.86 & 52.26 & -0.41 & 0.66 & $-3.457^{* *}$ & 44.48 & $-0.91[-1.47,-0.36]$ \\
& Virt. & 28 & 128.82 & 79.73 & 0.41 & 1.08 & & & \\
WP4 & Trad. & 28 & 111.11 & 86.48 & 0.04 & 0.98 & .299 & 54.00 & $0.08[-0.45,0.61]$ \\
& Virt. & 28 & 107.57 & 95.82 & -0.04 & 0.99 & & & \\
WP5 & Trad. & 28 & 103.93 & 102.21 & -0.24 & 0.97 & -1.838 & 54.00 & $-0.48[-1.02,0.05]$ \\
& Virt. & 28 & 144.82 & 105.86 & 0.24 & 0.96 & & & \\
WP6 & Trad. & 28 & 34.14 & 14.00 & 0.08 & 0.86 & .640 & 54.00 & $0.17[-0.36,0.7]$ \\
& Virt. & 28 & 32.57 & 24.21 & -0.08 & 1.10 & & & \\
PF & Trad. & 20 & 10.30 & 3.06 & -0.23 & 1.05 & -1.488 & 38.00 & $-0.46[-1.1,0.17]$ \\
& Virt. & 20 & 11.65 & 2.66 & 0.23 & 0.91 & & & \\
COD & Trad. & 20 & 47.73 & 24.60 & 0.25 & 1.27 & 1.602 & 26.25 & $0.50[-0.14,1.13]$ \\
& Virt. & 20 & 38.09 & 10.95 & -0.25 & 0.56 & & & \\
\hline
\end{tabular}

\subsection{Manipulation checks}

The two treatment groups were randomly assigned to testers as indicated by Table 4 . No statistical difference were found in the group assignment $\chi^{2}(4) 2.152, \mathrm{p}>.05$ or in the assignment to treatment groups across samples $\chi^{2}(3) 0.119, \mathrm{p}>.05$. 
Table 4 - Assignment of treatment groups to testers and days

\begin{tabular}{|c|c|c|c|c|c|c|c|c|c|c|c|}
\hline \multirow{2}{*}{ Treat } & \multicolumn{6}{|c|}{ Tester } & \multicolumn{5}{|c|}{ Sample } \\
\hline & 1 & 2 & 3 & 4 & 5 & Total & 1 & 2 & 3 & 4 & Total \\
\hline 1 & 7 & 4 & 5 & 7 & 5 & 28 & 6 & 5 & 9 & 8 & 28 \\
\hline 2 & 4 & 7 & 6 & 5 & 6 & 28 & 6 & 5 & 10 & 7 & 28 \\
\hline Total & 11 & 11 & 11 & 12 & 11 & 56 & 12 & 10 & 19 & 15 & 56 \\
\hline
\end{tabular}

Furthermore, there were no significant differences in the time scoring across testers $\mathrm{f}(4$, $51)=1.074, p>.05$ or in the utilization of time limits across testers $f(4,51)=1.646, p>.05$. Neither were there any difference in the order of testing between the two treatment groups $\mathrm{t}(54)=0.751, \mathrm{p}>.05$.

The two treatment groups were tested on visuospatial skills with the paper folding test (PF) and on FPP gaming skills by performing the introduction route on Call of Duty IV (COD). The correlational matrix in Table 5 indicates the relevance of these tests. According to Table 5, there were no statistically significant differences in PF or COD between the treatment groups.

Table 5 - Correlation matrix for Paper folding (PF), Call of Duty (COD) and Mean Way Point (MWP). All scores in z-scores.

\begin{tabular}{lcccc}
\hline Variable & & PF & COD & MWP \\
\hline PF & r & -- &,$- 399^{*}$ &,$- 462^{*}$ \\
& n & & 20 & 20 \\
COD & r &,$- 487^{*}$ & -- &, 233 \\
& n & 19 & & 20 \\
MWP & r &,- 343 &, $484^{*}$ & -- \\
& n & 20 & 20 &
\end{tabular}

Traditional condition above diagonal, Virtual condition below diagonal. ${ }^{*} \mathrm{p}<.05,{ }^{* *} \mathrm{p}<.01,{ }^{* * *} \mathrm{p}<.001$ (1-tailed).

\section{Discussion and Conclusion}

The results of the study demonstrate that there were no real differences between real and virtual familiarization. In terms of manipulation checks, the groups were equal on all measured pretests and no systematic biases were found in group allocation. A series of t-tests revealed no significant difference between the groups on the total time to find waypoints or a multiple choice measure on information given during the familiarization. Out of six waypoints used in the familiarization, only one waypoint revealed a significant better performance for traditional way finding $\mathrm{t}(48.036)=3.446, \mathrm{p}<.001, \mathrm{~g}=.89$. This waypoint was found to be poorly represented in the serious game.

\subsection{Hypothesis}

H1 stated that there is no overall difference between the virtual and the traditional familiarization condition on wayfinding time, which was supported in the current data set. Upon closer inspection of the MWP scores, the internal variations in the groups are strikingly high. This is somewhat counterintuitive, as the groups were homogenous student groups; we would expect even higher variations with a representative sample of the target population. However, it adds support to $\mathrm{H} 1$ in that individual differences are clearly more important than the mode of familiarization. The raw scores (Table 3) more clearly illustrates the real world 
significance of the difference. A mean difference of 11 seconds between the groups might be appear significant when the total mean times lie around 100 seconds, but that changes once we realize that the standard deviations of the treatment groups lie between 40 and 48 seconds.

This result corresponds to previous findings that virtual wayfinding can be equal to real world training (Williams et al 1997). However, the currents study bolsters this claim by a realistic testing of the all-important quality of most large ships: they are multi-level structures (Hölscher et al., 2006). Furthermore, although the current study is limited when compared to the existing body of literature in isolating single factors influencing spatial learning, it's core strength is that it is ecologically superior in bringing these factors together in a holistic test of virtual familiarization. This is valuable to practitioners, since different factors might combine in unpredictable ways to determine the learning quality of a real-world familiarization scheme.

$\mathrm{H} 2$ stated that there will be differences between the familiarization conditions for single waypoints. There is some support for this hypothesis in that WP3 (the Hospital) shows a significant difference. However, it can be argued that this result is the product of a poor game design rather than virtual familiarization being inherently inferior. WP3 and WP5 (Fire station 2) represent two opposing doors three meters apart on the real ship. Whereas the traditional familiarization dwells on the location of these doors being in close proximity, potentially increasing the retrieval cues for each post, the virtual familiarization is designed in a way that markers outside these doors are hit upon in close succession with no elaboration such that an interference effect may occur. This is in accordance with studies demonstrating interference of especially spatial information on spatial learning (Chrastil \& Warren, 2012). This particular issue could be easily fixed through refining the virtual reality design, however, as the HSE Simulator stands, this particular post is poorly covered within the virtual familiarization.

The rest of the posts show a balanced tendency to each of the familiarization modes, ranging from small to medium effects. Of the two medium effects, WP1(Exit 1) is favouring virtual familiarization. Two posthoc explanations can be given for this:

1. The simulator does not model the doors towards the muster station, thus facilitating the acquirement of survey knowledge by increasing visual access in accordance with Weisman (1981).

2. As the muster station is outside and in the vicinity of a large crane this area is potentially a hard hat area, leading the security officer to stop just inside of the muster station during the tour. This apparently led to some confusion in the traditional group about whether the muster station was in fact inside- or outside of the door.

WP5 favours traditional familiarization for the same reason as discussed for WP3 - they interfere with each other. However, as the wayfinders had by then already reinforced WP3, the difference is less for WP5. Again, the results for WP1 and WP5 are not statistically significant with the current sample size. This may mean that typical wayfinding posts are not very clearly favouring any one of the familiarization modes. Further studies with larger sample sizes are needed to conclude more decisively regarding these particular posts, but other posts should also be tested. Looking back to the Chrastil and Warren (2012) survey of the state of evidence concerning active and passive learning, the present study suffers the same drawback as even most studies reporting specifically on the dimension of activity: the experiment confounds the effect by failing to isolate different aspects of activity. When the present study then incorporates issues of activity together with different issues wayfinding in multi-level structures, as well as different obstacles for virtual immersion, it is perhaps hardly surprising that we end up with a null result; it would seem that with current technology, traditional and virtual familiarization are equal with different but often unpredictable pros and cons in a real world setting. 


\subsection{Manipulation Checks}

$\mathrm{COD}$ and PF were chosen as parameters to control for individual differences among the two control groups. Although the correlations between these parameters and MWP are lower than expected, significant correlations between PF and MWP for the traditional condition and between COD and MWP for the virtual condition indicates that they are relevant parameters for the manipulation checks (Table 5).

As indicated by Table 3, there were no statistically significant difference between the experimental groups, although the effect measures show moderate effects indicate that the individuals in the virtual condition had slightly better visuospatial- and gaming skills. These apparent contradictory results are readily understandable when we take into account the extensive variations within the groups. And although the differences are not statistically significant between the groups, the trend warrants comment because it could be seen to favour the virtual group. In fact, these results could be attributable to a design flaw in the experiment: $\mathrm{PF}$ and COD was measured after experimental treatment for logistical purposes and because they were assumed to measure stable skills not influenced by the experiment as it takes a lot more time to develop these skills. However, we must admit that spending time on the virtual condition which entails individual concentration tasks prior to the COD and PF test may have increased concentration and refurbished dormant gaming skills in the virtual group as opposed to the traditional group that were taken on a guided tour in groups. Hence, the PF and COD measures of the virtual group may have been positively biased. The lower standard deviations of the virtual group compared to the traditional group also supports this interpretation.

\subsection{Limitations}

The sample of the present study represents the target group for virtual familiarization, although they decidedly belong to the youngest cohort of that group. This means that older cohorts of the target group with less exposure to pc-based FPP gaming may be less susceptible to learning from virtual platforms, as previous studies have documented gaming proficiency to be of importance, although some mixed results indicate that nature of the experience and concrete aspects of the virtual task matters (see e.g. Okagaki \& French, 1994; Orvis, Horn, \& Belanich, 2007; Richardson, Powers, \& Bousquet, 2011; Subrahmanyam \& Greenfield, 1994). However, as indicated by reports of the growing gaming market of 35+ (Quantic Foundry, 2016), gaming experience amongst mariners are rapidly increasing. Also, extra numerals employed on constructions vessels like the Edda Fauna have a predominantly technical engineering background, viz. they are typically into computers and the concept of digitally rendered $3 \mathrm{~d}$ models and environments.

It is clear from the results that there are extensive individual variations, and more could have been done in measuring underlying variables such as visuospatial skills and gaming skills, as well as motivation in order to distil pure learning effects of the familiarization methods. However, mariners and other crew working on-board are not hired on the basis of such information, and so the variation in the sample reasonably reflects the variation in the population.

\subsection{Conclusion}

This paper found that there are no overall differences between using a virtual familiarization method to that of traditional, onboard familiarization, and that there are extensive individual variations related to familiarization. The study find some support for differences between the familiarization conditions for single waypoints. Still, poor design of the virtual environment may also explain this result. An inaccurate model in the virtual reality solution may explain the variance measured. A more decisive conclusion requires a larger sample size. 


\section{Acknowledgements}

The authors wish to thank the ship owner Østensjø Ltd. and its officers, administrative, and technical staff for facilitating the study; MARKOM2020 for funding the project; and $\mathrm{PhD}$ student Guro P. Fjeld and Technician Morten Mæland as well as several bachelor students at the Stord-Haugesund University College for participating as research assistants. Special thanks to Simsea's Boathy Murugendran who helped with the illustrations and all the students at the Stord-Haugesund University College and the students and lecturers at the Karmsund Highschool who participated and facilitated. Finally, this study would probably not have taken place without the early pilot project funding from the Norwegian Research Councils Program for Regional R\&D and Innovation (VRI) and the positive facilitation of Svein Rune Reinhardtsen at Virtech Ltd.

\section{References}

Batalden, B.M. Sydnes, A.K (2014). Maritime safety and the ISM code: a study of investigated casualties and incidents. WMU Journal of Maritime Affairs.Vol.13.pp.3-25.

Bavelier, D. and Green, C. (2016), The Brain-Boosting Power of Video Games, Scientific American, July, pp. 22-27

Bowman, D. and Hodges, L. (1997). "An Evaluation of Techniques for Grabbing and Manipulating Objects in Immersive Virtual Environments. ACM Proc. Symposium on Interactive 3D Graphics, Providence, pp. 35-ff.

Bowman, D., Davis, E., Badre, A., and Hodges, L. (1999). "Maintaining Spatial Orientation during Travel in an Immersive Virtual Environment", Presence: Teleoperators and Virtual Environments, N. 8, Vol. 6, pp. 618-631.

Bowman, D. A., Kruijff, E., LaViola Jr, J. J., \& Poupyrev, I. (2004). 3D user interfaces: theory and practice. Addison-Wesley.

Bowman, D., Koller, D., and Hodges, L. (1997). "Travel in Immersive Virtual Environments: An Evaluation of Viewpoint Motion Control Techniques", Proc. Virtual Reality Annual Symposium, Washington, March, page 45.

Bowman, D., Johnson, D., and Hodges, L. (2001). "Testbed Evaluation of Virtual Environment Interaction Techniques", Presence: Teleoperators and Virtual Environments, Vol. 10, N. 1, pp. 75-95.

Cherney, I. D. (2008). Mom, let me play more computer games: They improve my mental rotation skills. Sex Roles, 59, 776-786.

Chittaro, L. and Scagnetto, I. (2001). "Is Semitransparency Useful for Navigating Virtual Environments?", ACM Proc. Virtual Reality Software and Technology, Banif, pp. 159166.

Chrastil, E.R., \& Warren, W. H. (2012). Active and passive contributions to spatial learning. Psychonomic Bulletin \& Review, 19, 1-23.

Chrastil, E. R. and Warren, W. H. (2015). Active and passive spatial learning in human navigation: acquisition of graph knowledge. J. Exp. Psychol. Learn. Mem. Cogn. 41, 1162-1178. doi:10.1037/xlm0000082.

Cohen, J. (1988). Statistical power analysis for the behavioral sciences (Revised ed.). Hillsdale, NJ: Lawrence Erlbaum Associates. 
Curiel, J.M. \& Radvansky, G.A. (1998). Mental organization of maps. Journal of Experimental Psychology: Learning, Memory and Cognition, 24, 202-214.

Fairchild, K., Lee, B., Loo, J., Ng, H., and Serra, L. (1993). “The Heaven and Earth: Designing Applications for Novice Users”, IEEE Proc Virtual Reality Annual International Symposium, Seattle, September, pp. 47-53.

Feng, J., Spence, I., \& Pratt, J. (2007). Playing an action video game reduces gender differences in spatial cognition. Psychological Science, 18, 850-8553.

Hegarty, M., \& Waller, D. (2006). Individual differences in spatial abilities. In P. Shah \& A. Miyake (Eds.), Handbook of visuospatial thinking (pp. 121-169). New York: Cambridge University Press.

Howard, J. H. \& Kerst, S. M. (1981). Memory and Perception of Cartographic Information for Familiar and Unfamiliar Environments. Human Factors, Vol. 23, N. 4, pp 495-504.

Hölscher, C., Meilinger, T., Vrachliotis, G., Brösamle, M., \& Knauff, M. (2006). Up the down staircase: Wayfinding strategies in multi-level buildings. Volume 26, Journal of Environmental Psychology, 26, 284-299.

IMCA (2013) Guidance on Using the eCMID and the CMID Inspection Report Database. International Marine Contractors Association, London.

IMO (2011). STCW Convention - International Convention on Standards of Training, Certification and Watchkeeping for Seafarers, 1978. Including 2010 Manila Amendments. STCW Convention and STCW Code.3.Utgave. London:International Maritime Organization.

IMO (2014). ISM Code. International Safety Management Code and guidelines on implemention of the ISM Code. 2014 Edition.4.Utgave. London:International Maritime Organization.

Jadhav, P. and Kanse, Y. K. (2015), Sixth Sense Technology Based Pointer Interface System, International Journal on Recent and Innovation Trends in Computing and Communication, Vol 3, N. 3.

Klatzky, R., Loomis, J., Beall, A., Chance, S., and Golledge, R. (1998), Mental representations of Large and Small Spatial Layouts are Orientation Dependent, Psychological Science, Vol. 9, N. 4.

Mine, M. (1995). "Virtual Environment Interaction Techniques", University of North Carolina Computer Science Technical Report TR95-018.

Münzer, S., Zimmer, H. D., Schwalm, M., Baus, J., \& Aslan, I. (2006). Navigation assistance and the acquisition of route and survey knowledge. Journal of Environmental Psychology, 26, 300-308.

OCIMF (2010). Offshore Vessel Inspection Database - OVID. http://www.ocimfovid.com/Welcome.aspx. Accessed 14 December 2013.

OCIMF (2011). Offshore Vessel Inspection Database - Offshore Vessel Inspection Questionnaire. Oil Companies International Marine Forum, London.

Okagaki, L., \& Frensch, P. (1994). Effects of video game playing on measures of spatial performance: Gender effects in late adolescence. Journal of Applied Developmental Psychology, 15, 33-58.

Oldenburgh, M., Baur, X., Schlaich, C. (2010). Occupational Risk and Challenges of Seafaring. Journal of Occupational Health. Vol. 52, pp. 249-256. 
Orvis, K. A., Horn, D. B., \& Belanich, J. (2007). The roles of task difficulty and prior videogame experience on performance and motivation in instructional videogames. The 19th Annual Conference of the Association for Psychological Science, poster presentation, Washington DC.

Pausch, R., Burnette, T, Brockway, D., and Weiblen, M. (1995). Navigation and Locomotion in Virtual Worlds via Flight into Hand-Held Miniatures, ACM Proc. Siggraph'95, Los Angeles, pp. 399-400.

Poupyrev, I., Billinghurst, M., Weghorst, S., and Ichikawa, T. (1996). "The Go-Go Interaction Technique: Non-Linear Mapping for Direct Manipulation in VR", ACM Proc. Symposium on User Interface Software and Technology, Seattle, pp. 79-80.

Quantic Foundry (2016). The Growing 35+ Gamer Market. http://quanticfoundry.com/agereport/, accessed 20.12.2016.

Richard, P., Birebent, G., Coiffet, P, Burdea, G., Gomex, D., and Langrana, N. (1996). "Effect of Frame Rate and Force Feedback on Virtual Object Manipulation", Presence: Teleoperators and Virtual Environments, Vol. 5, N. 1. pp. 95-108.

Richardson, A. E., Powers, M. E., \& Bousquet, L. G. (2010). Video game experience predicts virtual, but not real navigation performance. Computers in Human Behavior, 27, 552560.

Sanchez, C., (2012) Enhancing visuospatial performance through video game training to increase learning in visuospatial science domains, Psychon. Bull. Rev. 19, 58-65.

Kum, S. Sahin, B. (2015), A root cause analysis for Arctic Marine accidents from 1993 to 2011. Safety Science, Vol.74, pp. 206-220.

Siegel, A. W., and White, S. H. (1975). The development of spatial representations of large scale environments. In H. W. Reese (Ed.), Advances in Child Development and Behavior, Vol. 10, (pp. 10-55). New York, NY: Academic Press.

Soeda, M., Kushiyama, N., Ohno, R. (1997). Wayfinding in Cases with Vertical Motion. Proceedings of MERA 97: Intern. Conference on Environment-Behavior Studies, 559564.

Subrahmanyam, K., \& Greenfield, P. M. (1994). Effect of video game practice on spatial skills in girls and boys. Journal of Applied Developmental Psychology, 15, 13-32.

Terlecki, M. S., Newcombe, N. S., \& Little, M. (2008). Durable and generalized effects of spatial experience on mental rotation: Gender differences in growth patterns. Applied Cognitive Psychology, 22, 996-1013

Tvedt, S. D., \& Oltedal, H. A. (2013). Evaluating the Edda Fauna HSE Simulator, Pilot study 1: Establishing familiarization trials and measures. (HSH-rapport nr. 02/13). Haugesund: Høgskolen Stord/Haugesund

Tversky, B. (2005), Cognitive maps, cognitive collages, and spatial mental models, Spatial Information Theory A Theoretical Basis for GIS. The series Lecture Notes in Computer Science, Vol. 716, pp. 14-24.

J. Viega, J., Conway, M.J., Williams, G., and Pausch, R. (1996). 3D magic lenses. ACM UIST'96 Proceedings, pp. 51-58.

Vaagland, I. I. E. (2014). Familiarisering av dekksoffiserer om bord på offshoreforsyningsfartøy. (Master Thesis, University of Tromsoe). Retrieved at http://munin.uit.no/bitstream/handle/10037/6842/thesis.pdf?sequence=1 
Weisman, J. (1981). Evaluating Architectural Legibility. Way-Finding in the Built Environment. Environment and behavior, 13, 189-204.

Ware, C. and Balakrishnan, R. (1994). Reaching for Object in VR Displays: Lag and Frame Rate, ACM Transactions on Computer-Human Interaction (TOCHI), Vol. 1, N. 4, 1994, pp. 331-356.

Williams, F. W., Tatem, P. A., Farley, CDR J. P., Tate, D. L., Sibert, L., King, LCDR T., Hewitt, D. H., Siegman, C. W. III, Wong, J. T., \& Toomey, LT T. A. (1997). Virtual Environment Firefighting/Ship Familiarization Feasibility Tests. NRL Technical Report 979861. Washington, DC: Naval Research Laboratory. 